\title{
Efeito da troca da firma de auditoria no gerenciamento de resultados das companhias abertas brasileiras
}

\section{Paulo Roberto da Cunha, Maurício Leite y Vânia Regina Moras}

Programa de Pós-Graduacao em Ciencias Contabeis e Administracao

Universidade Regional de Blumenau

O objetivo do presente estudo consiste em verificar o efeito da troca da firma de auditoria no nível de gerenciamento de resultados das companhias brasileiras listadas na BM\&FBovespa. Para tanto, realizou-se uma pesquisa descritiva, com abordagem quantitativa, por meio de pesquisa documental. A população da pesquisa compreendeu as companhias abertas brasileiras listadas na BM\&FBovespa no período de 2010 a 2016. Utilizou-se de regressão de dados em painel. Os resultados encontrados evidenciaram que as variáveis GROWTH (percentual de mudanças nas vendas) e TURN (vendas divididas pelos ativos totais no final do ano) foram significativas a nível de $99 \%$, o que permite afirmar que estas impactam no gerenciamento de resultados nas organizaçốes que compóe a amostra no período analisado. Em contrapartida, demais variáveis SIZE (logaritmo natural do ativo total), LEV (total do passivo dividido pelo total do patrimônio líquido no final do ano), DISSUE (percentual de mudanças no total dos passivos), CF (fluxo de caixa líquido anual das atividades operacionais divido pelos ativos totais no final do ano), AUD (empresa auditada por firma de auditoria Big-Four ou não) e TROFIRAUD (troca de firma de auditoria) não foram significativas.

Palavras-chave: auditoria, firma de auditoria, troca de auditoria, gerenciamento de resultados.

\section{Audit firm exchange effect on earnings management in listed companies brazilian companies}

The objective of this study is to verify the effect of the exchange of audit firm on earnings management level of Brazilian companies listed on the BM\&FBovespa. We conducted a descriptive with a quantitative approach by means of information retrieval. The research population comprised the Brazilian listed companies listed on the BM\&FBovespa from 2010 to 2016. Panel data regression was used. The findings showed that the GROWTH variables (percentage changes in sales) and TURN (sales divided by total assets at the end of the year) were significant at the level of 99\%, which allows us to state that these impacts the earnings management in the sample in the analyzed period. On the other hand, other variables SIZE (natural logarithm of total assets), LEV (total liabilities divided by total shareholders' equity at the end of the year), DISSUE (percentage of changes in total liabilities), CF (annual net cash operating activities divided by total assets at the end of the year), AUD (company audited by audit firm Big Four or not) and TROFIRAUD exchange (auditing firm) were not significant.

Keywords: Audit, audit firm, audit exchange, earnings management. 


\section{Efecto del cambio de la firma de auditoría en la gestión de resultados de las compañías abiertas brasileñas}

El objetivo del presente estudio consiste en verificar el efecto del cambio de la firma de auditoría en el nivel de gestión de resultados de las compañías brasileñas listadas en la BM\&FBovespa. Para ello, se realizó una investigación descriptiva, con abordaje cuantitativo, por medio de investigación documental. La población de la encuesta comprendió las compañías abiertas brasileńas listadas en la BM\&FBovespa en el período de 2010 a 2016. Se utilizó de regresión de datos en panel. Los resultados encontrados evidenciaron que las variables GROWTH (porcentaje de cambios en las ventas) y TURN (ventas divididas por los activos totales al final del año) fueron significativas a nivel del $99 \%$, lo que permite afirmar que éstas impactan en la gestión de resultados en las organizaciones que compone la muestra en el período analizado. En cambio, otras variables SIZE (logaritmo natural del activo total), LEV (total del pasivo dividido por el total del patrimonio neto al final del año), DISSUE (porcentaje de cambios en el total de los pasivos), CF (flujo de caja neta anual de las acciones las actividades operativas divididas por los activos totales al final del año), AUD (empresa auditada por firma de auditoría Big-Four o no) y TROFIRAUD (intercambio de firma de auditoría) no fueron significativas.

Palabras clave: auditoria, firma de auditoría, troca de auditoria, gerenciamento de resultados.

\section{Introdução}

A auditoria das demonstraçóes contábeis é o trabalho realizado por auditor independente que, após aplicação de um conjunto de procedimentos, emite um parecer sobre tais demonstraçóes a fim verificar sua adequação em conformidade com as Normas Brasileiras de Contabilidade (NBC) e demais legislaçóes vigentes (Cunha et al., 2011). A esse respeito, Marassi, Brizolla e Cunha (2014) argumentam que a apresentação de conclusões e opinióes dos auditores devem ser pautadas no conhecimento técnico, na postura ética e na independência do auditor.

Nesse sentido, a independência da auditoria é uma característica essencial para o desenvolvimento dos mercados de capitais eficientes; sendo que órgãos reguladores têm empenhado açóes para minimizar possíveis ameaças a esta independência. Assim, o nível de independência do auditor é definido como a probabilidade condicional que, caso uma falha ou violação tenha sido descoberta, o auditor reportará o fato (DeAngelo, 1981; Defond, Raghunandan \& Subramanyam, 2002).
Dessa forma, o pleno desenvolvimento das atividades dos auditores é fundamental para a emissão de uma opinião sobre a qualidade das informaçóes contábeis, na qual evidencia a realidade econômica e financeira das organizaçóes. No entanto, mesmo sujeita a aspectos subjetivos, característicos de tal atividade, a visão dos usuários das informações contábeis é que a opinião da auditoria expressa confiança da realidade econômica e financeira da empresa auditada (Firmino, Damascena \& Paulo, 2011).

Zhang, Zhou e Zhou (2007) argumentam que as receitas obtidas por outros serviços prestados pelas empresas de auditoria podem torná-la economicamente dependente da empresa auditada. Os autores explicam que quando há um forte vínculo econômico entre empresa de auditoria e empresa auditada, podem surgir incentivos em ignorar potenciais problemas, como por exemplo nos controles internos da organização, acarretando em uma perda da independência dos auditores.

Kinney, Palmrose e Scholz (2004) apresentam como consequência da perda da independência da auditoria 
a menor qualidade dos relatórios financeiros. Firmino, Damascena e Paulo (2011) consideram que uma auditoria independente contribui para a redução da assimetria informacional incorrida entre os usuários da informação. Acrescentam ainda que com a crescente necessidade por informaçóes mais oportunas e seguras vem exigindo maior qualidade nos serviços realizados pelos auditores.

Após as descobertas de fraudes financeiras envolvendo respeitadas corporaçóes e auditores, nos Estados Unidos da América foi aprovada a Lei Sarbanes-Oxley (SOX), que entrou em vigor em julho de 2002 para lidar principalmente com a crescente preocupação dos investidores sobre a integridade dos relatórios financeiros das empresas (Defond, Raghunandan \& Subramanyam, 2002; Zhang, Zhou \& Zhou, 2007; Silva \& Robles Junior, 2008; Firmino, Damascena \& Paulo, 2011). Murcia, Borba e Schiehll (2008) destacam que estes escândalos resultaram na perda da credibilidade das demonstraçóes contábeis como instrumento de divulgação de informações aos usuários externos.

Silva e Bezerra (2010) acreditam que a troca da firma de auditoria contribui para o aumento da independência entre a firma de auditoria e a empresa auditada. Nesse sentido, espera-se que o novo auditor seja cético em relação à qualidade das demonstrações contábeis, sobretudo para a prática do gerenciamento de resultados. Schipper (1989) e Healy e Wahlen (1999) indicam que o gerenciamento de resultados é a intervenção, realizada propositalmente, com a intenção de obter algum ganho, que ocorre quando os administradores utilizam de julgamentos sob as informaçóes financeiras e operacionais da empresa, na intenção de alterá-las sobre o desempenho econômico da companhia.
Martinez (2001) expóe que apesar de ser uma alteração proposital, o gerenciamento de resultados não é considerado fraude contábil, pois os gestores buscam atuar de forma que a legislação permite com certa discricionariedade. Assim, espera-se que o auditor se mantenha cético diante da prática de gerenciamento de resultados, o qual pode ser utilizado pelo gestor em benefício próprio.

A auditoria pode contribuir para minimizar as práticas de gerenciamento de resultados, sendo reforçada pelo rodízio da firma de auditoria. No cenário mundial poucos países possuem a obrigatoriedade de realizar a mudança da firma de auditoria, já no Brasil, esta obrigatoriedade tornou-se um cenário ideal para avaliar se a qualidade das informaçóes contábeis é impactada pela mudança da firma de auditoria. No entanto, as evidências encontradas até o momento não permitem afirmar que há impacto na qualidade da informação contábil após a troca da firma de auditoria. Tais resultados levantam um questionamento sobre a instituição do rodízio obrigatório, propiciando oportunidades de pesquisa nesse tema no Brasil (Azevedo \& Costa, 2012).

Sob tais perspectivas, esta pesquisa apresenta a seguinte questáo de pesquisa: qual o efeito da troca de firma de auditoria no nível de gerenciamento de resultados nas companhias brasileiras listadas na BM\&FBovespa? Dessa forma, o objetivo do presente estudo consiste em verificar o efeito da troca da firma de auditoria no nível de gerenciamento de resultados das companhias brasileiras listadas na BM\&FBovespa.

Conforme apontado por Quevedo e Pinto (2014), a temática rodízio de auditoria continua sendo um assunto polêmico, que gera uma divergência muito significativa entre a opinião de diversas classes envolvidas em aspectos contábeis, de auditoria e do próprio 
rodízio em si. Por outro lado, Dani, Panucci Filho, Santos e Klann (2017), as alterativas de gestão que permitam os administradores a gerenciar resultados contábeis de interesse na literatura internacional. Além disso, a originalidade deste estudo consiste no uso do modelo de gerenciamento de resultados proposto por Barth, Landsman e Lang (2008) com a troca de empresas de auditoria no contexto brasileiro.

Neste sentido, o presente trabalho justifica-se pela carência de estudos empíricos, principalmente no contexto brasileiro, que analisem em uma mesma perspectiva o rodízio de empresas de auditoria e o gerenciamento de resultados. Destaca-se ainda que estudos nacionais, tais como Martinez e Reis (2011), Silva e Bezerra (2010), Azevedo e Costa (2012), dentre outros, verificaram a troca de firma de auditoria no gerenciamento de resultados até o ano de 2008. Sendo assim, esta pesquisa visa abordar os períodos que sucedem o ano de 2008 para verificar o efeito da troca de firma de auditoria no gerenciamento de resultados, buscando contribuir para com a literatura no sentido de ampliar a discussão relacionada à temática proposta.

\section{Revisão de literatura}

Nesta revisão de literatura são abordados temas que embasam conceitualmente a problemática da pesquisa em questão. Inicialmente são apresentadas informaçôes acerca do rodízio das firmas de auditoria, seguida da discussão acerca do gerenciamento de resultados, finalizando com estudos relacionados ao tema.

\subsection{Rodízio de firma de auditoria}

A evolução da ciência contábil permitiu o desenvolvimento da técnica de auditoria, sendo está voltada a orientação, interpretação e de previsão de fatos, tornando-se dinâmica e em constante transformação.

Dessa forma, Mattos (2005) define auditoria como sendo o processo de levantamento, estudo e avaliação sistemática de transaçóes, procedimentos, rotinas e demonstraçôes contábeis de uma entidade, que objetiva fornecer aos usuários uma opiniáo imparcial e fundamentada em normas e sobre sua adequação.

Medidas regulatórias têm sido implementadas para melhorar a qualidade das auditorias corporativas, dentre elas, o rodízio obrigatório das firmas de auditoria. As disposições legais em diferentes países referentes ao rodízio obrigatório têm gerado opinióes divergentes quanto a sua efetividade, principalmente porque a maioria dos sistemas jurídicos permite a livre escolha dos auditores (Quevedo \& Pinto, 2014).

Há fatores importantes acerca do rodízio obrigatório de firmas de auditoria a serem considerados, dentre eles o custo de auditoria e a qualidade do serviço. Especificamente sobre a qualidade da auditoria, Arruñada e Paz-Arez (1997) argumentam que o rodízio prejudica dois dos principais determinantes da qualidade; competência técnica do auditor, pois sua capacidade de detectar irregularidades nas demonstraçóes financeiras é dificultada pelo maior número de auditorias iniciais e menor grau de especializaçáo, e a independência do auditor.

Segundo Catanach Jr. e Walker (1999), as crises organizacionais têm sido atribuídas a má qualidade da auditoria associada a uma percepçáo de falta de independência dos auditores. Além disso, falhas podem ocorrer devido ao fato de os auditores não detectarem ou em náo reportarem erros materiais nas demonstrações financeiras. Em contrapartida, os autores argumentam que o rodízio obrigatório das firmas de auditoria tem sido sugerido como um meio de reforçar a independência e reduzir a incidência de falhas de auditoria. 
A regra de rotatividade obrigatória da firma de auditoria, que estabelece um limite máximo de anos para auditar as demonstraçóes financeiras de uma determinada empresa, tem sido proposta como um meio para preservar a independência do auditor e, possivelmente, para aumentar a confiança dos investidores nos relatórios financeiros (Chi et al., 2009; Said \& Khasharmeh, 2014). As vantagens e desvantagens da obrigatoriedade desta rotação têm sido intensamente debatida, mas existe pouca evidência em pesquisas empíricas que avaliam os custos, benefícios e eficácia de tal rotatividade. Oliveira e Santos (2007) destacam os principais aspectos positivos e negativos sobre o rodízio de auditoria, conforme destacado no quadro 1 .
Azevedo e Costa (2012) apontam que, longos períodos de relacionamento entre auditor e clientes podem colaborar para a redução da independência do auditor, por outro lado, a qualidade da auditoria pode ser impactada negativamente pela falta de conhecimentos sobre as atividades dos novos clientes. Dessa forma, a troca de auditor poderia contribuir para a redução da qualidade das demonstraçóes contábeis pelo tempo de aprendizado necessário para a adequada compreensão das transaçōes ocorridas.

Conforme Quevedo e Pinto (2014), os principais órgãos contábeis, como o Conselho Federal de Contabilidade e o Instituto Brasileiro de Contadores,

\section{Quadro 1. Aspectos positivos e negativos do rodízio de firmar de auditoria}

\begin{tabular}{|c|c|}
\hline Aspectos Positivos & Aspectos Negativos \\
\hline $\begin{array}{l}\text { Socializa o conhecimento técnico pois quebra o monopólio do } \\
\text { conhecimento e da prática de auditoria em determinado seg- } \\
\text { mento }\end{array}$ & $\begin{array}{l}\text { Não mantém o conhecimento acumulado da firma de auditoria que } \\
\text { tem feito os trabalhos. O foco dos trabalhos do novo auditor pode náo } \\
\text { ser direcionado para áreas de risco }\end{array}$ \\
\hline $\begin{array}{l}\text { Satisfaz o público com a quebra de relacionamento de longo } \\
\text { prazo, conferindo a determinados usuários das demonstraçôes } \\
\text { contábeis uma percepção de maior independência }\end{array}$ & $\begin{array}{l}\text { Desestabiliza a relação econômica entre as partes. No primeiro ano } \\
\text { de trabalho, é realizado um investimento considerável pelas firmas } \\
\text { na expectativa de ser recuperado em anos subsequentes por trabalhos } \\
\text { mais eficientes e mais bem planejados }\end{array}$ \\
\hline $\begin{array}{l}\text { Muda o perfil do auditor nas empresas submetidas ao rodízio. } \\
\text { Um perfil mais técnico do auditor é privilegiado em detrimento } \\
\text { do perfil comercial e gerador de novos trabalhos }\end{array}$ & $\begin{array}{l}\text { Redução dos investimentos em especialização dos auditores, pois as } \\
\text { firmas não alocariam recursos na formaçâo técnica, sem a certeza de } \\
\text { que a interrupção do relacionamento ocorreria por circunstâncias nor- } \\
\text { mais, e não por decisão regulatória }\end{array}$ \\
\hline $\begin{array}{l}\text { Requer maior atenção do auditor pelo processo de troca, pela } \\
\text { exposição de seus papéis de trabalho a outros auditores, suces- } \\
\text { sores ou revisores }\end{array}$ & $\begin{array}{l}\text { A governança corporativa é afetada, pois liberdade de escolha estaria } \\
\text { sendo impactada em sua essência }\end{array}$ \\
\hline $\begin{array}{l}\text { Focaliza a atenção do auditor no acionista, e não na adminis- } \\
\text { traçáo }\end{array}$ & $\begin{array}{l}\text { Desequilibra o mercado das firmas, pois a busca pela recomposição } \\
\text { de carteiras de clientes seria estruturada de forma inadequada, sem } \\
\text { respeitar as condiçóes normais de mercado }\end{array}$ \\
\hline $\begin{array}{l}\text { Muda a metodologia de auditoria com foco concentrado nos } \\
\text { procedimentos obrigatórios e maior objetividade na alocaçáo e } \\
\text { no foco dos testes de auditoria }\end{array}$ & $\begin{array}{l}\text { A carreira em auditoria seria dificultada, pois a perda desses clientes } \\
\text { pode propiciar até mesmo a interrupçáo da prática de auditoria de } \\
\text { firmas }\end{array}$ \\
\hline $\begin{array}{l}\text { Suaviza a falta de fiscalização por parte dos órgãos fiscalizadores, } \\
\text { pois a possibilidade de o auditor sucessor ter acesso aos papéis } \\
\text { de trabalho referentes ao processo de auditoria das demons- } \\
\text { traçóes contábeis das empresas pode ser considerada uma forma } \\
\text { de fiscalizaçáo adicional, que deveria ser feita por tais órgãos }\end{array}$ & \\
\hline
\end{tabular}

Fonte: Oliveira e Santos (2007). 
são contrários ao rodízio de firmas de auditoria, por considerarem que há muitos fatores negativos, como o alto custo proporcionado pela mudança, comparativamente aos seus benefícios. Porém, os autores ao avaliarem a percepção do rodízio de auditoria sob o olhar dos auditores independentes, descobriram que $91 \%$ destes são favoráveis ao rodízio de auditoria e $56 \%$ acreditam que as melhorias proporcionadas pelo rodízio superam seus custos.

Para Lopes e Tukamoto (2007), após os escândalos contábeis que envolveram empresas como a Enron e WorldCom, abriu-se um leque de questionamentos sobre a ética corporativa e os mecanismos de governança, que por consequência passaram a motivar estudos sobre o gerenciamento de resultados. Sob esse aspecto, Azevedo e Costa (2012) argumentam que a troca da firma de auditoria contribui para o aumento da independência e, por consequência, um menor nível de gerenciamento de resultados.

\subsection{Gerenciamento de resultados}

O gerenciamento de resultados é a intervenção realizada, de forma proposital, no processo de evidenciação externa, com a intenção de obter algum ganho privado (Schipper, 1989). Segundo Healy e Wahlen (1999), o gerenciamento de resultados ocorre quando gestores se utilizam de julgamentos acerca das informaçóes financeiras, bem como das atividades operacionais da empresa para, intencionalmente, alterar o desempenho econômico da companhia.

Já Martinez (2006) e Bispo e Lamounier (2011) destacam que o gerenciamento de resultados (earning management) caracteriza-se como a alteração intencional dos resultados contábeis dentro dos limites legais e da flexibilidade permitida pelas normas contábeis para atender às motivaçóes particulares. Neste contexto, gestores podem manipular o verdadeiro desempenho da empresa, atribuindo valores que náo expressam a realidade empresarial. Essa prática, consequentemente, contribui para o aumento da assimetria informacional e induz os gestores a tomarem decisóes inadequadas.

Para Coelho e Lopes (2007), as práticas contábeis devem atender à postura de eficiência econômica e à maximização do valor da empresa. Sendo assim, gestores podem agir de forma a maximizar seus próprios interesses, posicionando-se de forma oportuna e escolhendo determinadas práticas contábeis, especialmente as que minimizem os custos contratuais e de transação da empresa. Bispo e Lamounier (2011) acrescentam que ajustes contábeis podem ser utilizados para suavização de lucros em relaçáo aos fluxos de caixa bem como para alterar as decisóes econômicas da empresa.

Martinez (2008) apresenta a diferença entre o lucro líquido e o fluxo de caixa operacional líquido como accrual (acumulaçóes), ou seja, referem às contas de resultado que influenciam o lucro da empresa, e que não implicam na movimentação dos fluxos de caixa. Neste caso, o lucro é mensurado no sentido econômico de acrescer riqueza patrimonial na empresa, independente de movimentaçáo financeira. Para isso, o gestor discricionariamente aumenta ou diminui os accruals com o intuito de impactar no lucro.

Os accruals são divididos em accruals discricionários, cujo propósito é gerenciar o resultado contábil, e accruals não discricionários, inerentes à realidade do próprio negócio. Portanto, "os accruals discricionários são uma proxy do gerenciamento de resultados contábeis", eles podem ser positivos ou negativos representando respectivamente a forma que a empresa está gerenciando-os para melhor ou para pior (Martinez, 2008, p. 8). Por meio das movimentaçôes realizadas pelos gestores, evidenciaram-se três modalidades de gerenciamento de resultados contábeis, o qual são apresentados no quadro 2 . 
Quadro 2. Modalidades de gerenciamento de resultados contábeis

\begin{tabular}{|l|l|l|}
\hline \multicolumn{1}{|c|}{ Target Earnings } & Income Smoothing & $\begin{array}{l}\text { Take a Bath / Big } \\
\text { Bath Accounting }\end{array}$ \\
\hline $\begin{array}{l}\text { Gerenciamento } \\
\text { de resultados para } \\
\text { aumentar ou dimi- } \\
\text { nuir os lucros, no } \\
\text { intuito de atingir as } \\
\text { metas desejadas }\end{array}$ & $\begin{array}{l}\text { Gerenciamento } \\
\text { de resultados para } \\
\text { reduzir sua variabi- } \\
\text { lidade e mantê-los } \\
\text { em determinado } \\
\text { patamar para evitar } \\
\text { flutuaçóes }\end{array}$ & $\begin{array}{l}\text { Gerenciamento de } \\
\text { resultados contá- } \\
\text { beis para reduzir } \\
\text { lucros correntes } \\
\text { com o propósito de } \\
\text { melhorar os resul- } \\
\text { tados no futuro }\end{array}$ \\
\hline
\end{tabular}

Fonte: Martinez (2001).

As modalidades de gerenciamento de resultados contábeis auxiliam os gestores a direcionar suas tomadas de decisóes, nesse sentido, a qualidade do resultado contábil é vista como uma medida para a assimetria informacional, sendo que a empresa passa a influenciar os usuários das informaçôes contábeis em suas decisôes, que modifica seu julgamento sobre a verdadeira situação da empresa (Martinez, 2001, Bispo \& Lamounier, 2011).

Bispo e Lamounier (2011) comentam que analistas, investidores bem como profissionais ligados às empresas, possuem interesse em verificar em quanto os resultados são manipulados, devido aos recentes colapsos de organizaçóes que foram encobertos pelas manipulaçóes nas demonstraçóes financeiras, afetando a qualidade das informaçóes contábeis divulgadas. Martinez (2008) argumenta que o gerenciamento de resultado, compromete a qualidade da informação contábil.

Nesse contexto, Azevedo e Costa (2012) acreditam que a rotatividade periódica do auditor propicia melhorar a qualidade dos serviços prestados pelas empresas de auditoria, por meio do aumento da independência dos auditores. De forma inversa, quando os auditores prestam serviços para as empresas durante vários anos, haverá um aumento nos riscos de falhas acontecerem e consequentemente reduzir a qualidade da auditoria.
Em relação às práticas de gerenciamento de resultados, evidencia-se na literatura diferentes modelos, tais como o de Healy (1985), DeAngelo (1986), Dechow e Sloan (1991), Jones (1991), Dechow, Sloan e Sweeney (1995) - ou Jones Modificado -, Kang e Sivaramakrishnan (1995) - ou modelo KS -, Pae (2005), Leuz, Nanda e Wysocki (2003), Barth, Landsman e Lang (2008), dentre outros.

Com o intuito de alcançar o objetivo proposto por este estudo, que consiste em verificar o efeito da troca da firma de auditoria no nível de gerenciamento de resultados das companhias brasileiras listadas na BM\&FBovespa, adotou-se o modelo de Barth, Landsman e Lang (2008). Tal modelo foi desenvolvido para testar o impacto do processo de convergência contábil internacional na qualidade contábil, utilizando como proxy da qualidade contábil o gerenciamento de resultados.

No entendimento de Barth, Landsman e Lang (2008), quanto maior o nível de gerenciamento de resultados, menor é a qualidade contábil. Uma das métricas de utilizadas neste modelo é a variabilidade das mudanças no lucro líquido dividido pelos ativos totais $(\Delta \mathrm{NI}$ - $\Delta$ net income). Os autores explicam que uma pequena variância nas mudanças no lucro líquido pode ser considerada como evidência de suavização de resultados.

O modelo de gerenciamento de resultados proposto por Barth, Landsman e Lang (2008) foi utilizado no contexto brasileiro por estudos empíricos como o de Klann e Beuren (2015) que objetivou comparar os efeitos do processo de convergência contábil internacional nos níveis de gerenciamento de resultados entre as empresas brasileiras e inglesas, assim como o de Bonfim, Silva, Gonçalves e Silva (2016) cujo objetivo foi o de verificar se com a evolução da adoção das normas internacionais de contabilidade (período pós 
IFRS), as seguradoras brasileiras diminuíram o nível de suavização dos resultados.

Desta forma, nesta pesquisa também se adotou o modelo Barth, Landsman e Lang (2008) para verificar o efeito da troca de firma de auditoria no gerenciamento de resultados das empresas brasileiras listadas na BM\&FBovespa. Na próxima seção apresenta-se estudos relacionados ao qual embasarão os resultados alcançados por esta pesquisa.

\subsection{Estudos anteriores sobre Rodízio de Auditores e gerenciamento de resultados}

Na pesquisa de Becker, DeFond, Jiambalvo e Subramanyam (1998) foi analisado a relação entre a qualidade da auditoria e o gerenciamento de resultado. A amostra foi composta por 10.379 empresas auditadas por firmas de auditoria Big Six e 2.179 empresas auditadas por não Big Six, no período de 1989 a 1992. Os resultados demonstram que não foi possível confirmar que as Big Six estão propícias a apresentar uma melhor qualidade e um menor gerenciamento de resultados em relação as firmas de auditoria não Big Six.

Silva e Bezerra (2010) verificaram a existência da relação entre o rodízio de empresas de auditoria e o gerenciamento de resultados nas empresas de capital aberto da BM\&FBovespa. A amostra foi composta por três empresas de cada setor econômico que apresentavam o maior ativo total no exercício de 2008, excluindo o setor financeiro. Foram coletados dados das demonstraçóes contábeis no período de 2000 a 2008. Os resultados demostram que houve uma reduçáo de $21 \%$ do ano anterior a troca para o ano da troca de auditoria. Setores como petróleo, gás e biocombustíveis, materiais básicos consumo não cíclico, telecomunicaçóes e utilidade pública verificou-se a suavização do gerenciamento de resultados com a troca da firma de auditoria. Os resultados alcançados não permitem afirmar que a troca de firma de auditoria independente está diretamente relacionada à diminuição do gerenciamento de resultados.

Martinez e Reis (2011) investigaram a relação entre o rodízio do auditor independente e a propensão das empresas brasileiras em gerenciar resultado. Analisaram uma amostra de empresas não financeiras com açôes listadas na Bolsa de São Paulo (BOVESPA) entre 1997 e 2007. Os resultados indicam que não há efeito significativo no gerenciamento de resultados na troca de firma de auditoria nas empresas.

Azevedo e Costa (2012) analisaram o efeito das mudanças de firma de auditoria no gerenciamento de resultados das companhias abertas brasileiras, em uma amostra de 98 empresas no período de 1998 a 2005. Os resultados apontaram que a troca de firma de auditoria náo impacta no nível do gerenciamento de resultados, as mudanças obrigatórias de firma de auditoria também não apresentaram diferenças no nível de gerenciamento de resultados em relação a troca compulsória da auditoria. Os resultados que apresentaram diferenças nos níveis de gerenciamento de resultados referem-se aos anos que antecedem a troca quando ela é obrigatória. O tipo de troca de firma de auditoria, por exemplo, Big-Four ou não Big-Four náo impactam no nível de gerenciamento de resultados.

Estes estudos encontrados na literatura nacional destacam pesquisas que analisam o efeito da troca da firma de auditoria no gerenciamento de resultados até o período de 2008. Portanto, o presente estudo busca verificar o efeito da troca de firma de auditoria no gerenciamento de resultados no período de 2010 a 2016. A escolha do corte temporal objetiva mitigar eventuais problemas na mensuraçáo das medidas contábeis. 


\section{Aspectos metodológicos}

Para verificar o efeito da troca da firma de auditoria no nível de gerenciamento de resultados das companhias brasileiras listadas na BM\&FBovespa, realizou-se uma pesquisa descritiva, com abordagem quantitativa, por meio de pesquisa documental.

A população da pesquisa compreendeu as companhias abertas brasileiras listadas na BM\&FBovespa no período de 2010 a 2016. Para formar a amostra, considerou-se somente as companhias ativas no ano de 2017 e que possuem dados suficientes disponíveis na base de dados Economática ${ }^{\oplus}$. Além disso, foram desconsideradas as empresas pertencentes ao setor financeiro por apresentarem características diferentes das demais empresas que compóem a amostra na tentativa de eliminar os efeitos do referido setor no gerenciamento de resultados. A tabela 1 demonstra a quantidade de empresas na qual satisfazem os critérios de seleçáo da amostra do período analisado.

Conforme se pode observar na tabela 1 , no período analisado, obteve-se 1620 observaçóes. Ademais, a amostra é não balanceada, ou seja, nem todas as empresas possuíam informaçóes em todos os anos. Dessa forma, foram analisadas 264 diferentes empresas. Os dados contábeis foram coletados na base de dados Economática ${ }^{\circledR}$ e os dados referentes às empresas de auditoria (Big Four ou não) e se houve troca de firma de auditoria (ou não) foram coletados no sítio da BM\&FBovespa (2017), especificamente nos Relatórios de Referência em setembro de 2017.

Para verificar o gerenciamento de resultados utilizou-se o Modelo de Barth, Landsman e Lang (2008). Os autores interpretam que uma pequena variância nas mudanças no lucro líquido pode ser considerada como evidência de suavização de resultados. Barth, Landsman e Lang (2008) excluíram da variável $\Delta \mathrm{NI}$ os resultados extraordinários e não operacionais, em razão de que esses valores poderiam apresentar diferenças significativas entre as empresas, o que poderia distorcer os resultados. Sendo assim, nesta pesquisa, utilizou-se o Lucro Operacional das empresas como variável $\Delta \mathrm{NI}$, não considerando, então, os itens extraordinários e não operacionais. Essa sistemática foi utilizada por Klann e Beuren (2015) e Bomfim et al. (2016) que descrevem que quanto menor a variabilidade, maior a evidência de gerenciamento de resultados. Assim, as empresas com menor suavização de resultados apresentam maior volatilidade nos lucros e consequentemente quanto maior a volatilidade nos lucros menor o nível de gerenciamento de resultados. A equação 1 representa a variabilidade das mudanças no lucro operacional, conforme segue:

Tabela 1. Composição da amostra

\begin{tabular}{|l|c|c|c|c|c|c|c|}
\hline \multicolumn{1}{|c|}{ Itens } & $\mathbf{2 0 1 0}$ & $\mathbf{2 0 1 1}$ & $\mathbf{2 0 1 2}$ & $\mathbf{2 0 1 3}$ & $\mathbf{2 0 1 4}$ & $\mathbf{2 0 1 5}$ & $\mathbf{2 0 1 6}$ \\
\hline População total & 372 & 372 & 372 & 372 & 372 & 372 & 372 \\
\hline (-) Empresas financeiras & 83 & 83 & 83 & 83 & 83 & 83 & 83 \\
\hline (-) Empresas com patrimônio líquido a descoberto & 20 & 20 & 22 & 23 & 24 & 37 & 43 \\
\hline (-) Empresas sem dados completos & 49 & 39 & 36 & 29 & 25 & 19 & 17 \\
\hline (=) Amostra final & 220 & 230 & 231 & 237 & 240 & 233 & 229 \\
\hline No total de observaçóes & & \multicolumn{2}{|c|}{1620} \\
\hline
\end{tabular}

Fonte: Dados da pesquisa. 
$\Delta N I_{p n}=\left(\frac{L O p_{n}}{A T_{n}}-\frac{L O p_{n-1}}{A T_{n-1}}\right)$

Onde:

$\Delta N I_{p n}=$ Variabilidade no Lucro Operacional Líquido; $L O_{p n}=$ Lucro Operacional Líquido no período 1;

$L O_{p n-1}=$ Lucro Operacional Líquido no período 0;

$A T_{n}=$ Ativo Total no período 1; e

$A T_{n-1}=$ Ativo Total no período 0 .

Para verificar o efeito da troca de firma de auditoria no gerenciamento de resultados utilizou-se o seguinte modelo (1) de regressão:

$$
\begin{aligned}
& \Delta N I_{i t}=\alpha_{0}+\alpha_{1} \text { SIZE }_{i t}+\alpha_{2} \text { GROWTH }_{i t} \\
& +\alpha_{3} L E V_{i t}+\alpha_{4} \text { DISSUE }_{i t}+\alpha_{5} \text { TURN }_{i t} \\
& +\alpha_{6} \text { CF }_{i t}+\alpha_{7} \text { AUD }_{i t}+\alpha_{8} \text { TROFIRAUD }_{i t}+\varepsilon_{i t} \text { (Modelo1) }
\end{aligned}
$$

Onde:

$\Delta N I_{p n}=$ Variabilidade no Lucro Operacional Líquido; $S I Z E=$ Logaritmo natural do ativo total;

$G R O W T H=$ Percentual de mudanças nas vendas;

$L E V=$ Total do passivo dividido pelo total do patrimônio líquido no final do ano;

DISSUE = Percentual de mudanças no total dos passivos;

$T U R N=$ Vendas divididas pelos ativos totais no final do ano;

$C F=$ Fluxo de caixa líquido anual das atividades operacionais divido pelos ativos totais no final do ano; $A U D=$ Variável dicotômica, sendo 1 para empresa auditada por firma de auditoria Big-Four (PricewaterhouseCoopers, KPMG, Ernst\&Young ou Deloitte Touche Tohmatsu) e zero para outras firmas de auditoria; $\mathrm{e}$

TROFIRAUD = Variável dicotômica, sendo 1 para ano da troca de firma de auditoria e zero para o ano em que náo houve troca de firma de auditoria.
Para verificar o efeito da troca de firma de auditoria no gerenciamento de resultados das empresas que compôem a amostra do presente estudo conforme Modelo 1 proposto, utilizou-se de regressáo de dados em painel por meio do software estatístico Stata ${ }^{\circledR}$ versão 13.

\section{Descrição e análise dos resultados}

Os dados apresentados foram coletados e analisados a partir do que se determinou nos procedimentos metodológicos e, em conformidade com o objetivo proposto neste estudo. O primeiro tópico refere-se a estatística descritiva e o segundo tópico contempla a análise do modelo de regressão por meio de dados em painel.

\subsection{Estatística descritiva da amostra}

Primeiramente realizou-se a análise descritiva das companhias brasileiras ativas e, 2017 e listadas na BM\&FBovespa. Dessa forma, a tabela 2 apresenta as empresas que compóem a amostra do estudo, subdividida pelos seus respectivos setores. Considerou-se a classificação dos setores conforme especificado pela BM\&FBovespa.

\section{Tabela 2. Empresas que compóem amostra}

\begin{tabular}{|l|c|c|}
\hline \multicolumn{1}{|c|}{ Setor } & Qtde & $\%$ \\
\hline Bens Industriais & 51 & $19 \%$ \\
\hline Consumo Cíclico & 74 & $28 \%$ \\
\hline Consumo não Cíclico & 22 & $8 \%$ \\
\hline Materiais Básicos & 30 & $11 \%$ \\
\hline Petróleo, Gás e Biocombustíveis & 10 & $4 \%$ \\
\hline Saúde & 13 & $5 \%$ \\
\hline Tecnologia da Informação & 9 & $3 \%$ \\
\hline Telecomunicaçóes & 5 & $2 \%$ \\
\hline Utilidade Pública & 49 & $19 \%$ \\
\hline Total Geral & 264 & $100 \%$ \\
\hline
\end{tabular}

Fonte: Dados da pesquisa. 
Como se pode observar na tabela 2 , a composição das empresas que compóem a amostra da pesquisa corresponde a 264 diferentes empresas no período analisado (2010 a 2016). Essas empresas estão distribuídas em 9 setores econômicos, com destaque para o setor de Consumo Cíclico representado por 74 empresas, o que corresponde a $28 \%$ do total, seguido do setor de Bens Industriais com 51, o que representa 19\%, 49 empresas do setor de Utilidade Pública, o que representa 19\% e o setor de Materiais Básicos com 30 empresas, correspondente a $11 \%$. Estes quatro setores representam $77 \%$ da amostra total. Outros 33\% das empresas que compóem a amostra estão divididas em outros cinco setores. A tabela 3 apresenta a quantidade de troca de firmas de auditoria pelas empresas da amostra.

Tabela 3. Troca da firma de auditoria

\begin{tabular}{|l|c|c|c|c|c|c|}
\hline $\begin{array}{c}\text { No Troca de } \\
\text { Firma Auditoria }\end{array}$ & Nenhuma & Uma & Duas & Três & Quatro & Cinco \\
\hline No Empresas & 12 & 101 & 127 & 9 & 4 & 1 \\
\hline
\end{tabular}

Fonte: Dados da pesquisa.

Observa-se na Tabela 3 que no período em análise, 101 empresas realizaram ao menos uma troca, 127 empresas realizaram duas trocas, 9 empresas realizaram três tocas, 4 empresas efetuaram quatro trocas e por fim, 1 empresa realizou cinco trocas de empresas de auditoria. Destaca-se, porém, que 12 empresas analisadas não efetuaram nenhuma troca de firma de auditoria durante o período (7 anos), ou seja, essas organizações não estão atendendo a legislação quanto a obrigatoriedade do rodízio de firma de auditoria conforme preconizado pela Instrução CVM no 308 de 15 de maio de 1999 (CVM, 2017). A tabela 4 apresenta a quantidade de empresas que fizeram a troca de firma de auditoria evidenciada anualmente.

\section{Tabela 4. Ano da troca de firma auditoria}

\begin{tabular}{|l|c|c|c|c|c|c|c|}
\hline Ano da Troca & 2010 & 2011 & 2012 & 2013 & 2014 & 2015 & 2016 \\
\hline $\begin{array}{l}\text { Número de } \\
\text { empresas }\end{array}$ & 27 & 41 & 52 & 37 & 37 & 31 & 34 \\
\hline
\end{tabular}

Fonte: Dados da pesquisa.

Conforme apresentado na tabela 4, pode-se observar que o ano de 2012 foi o ano em que houve o maior número de empresas que efetuaram a troca de firmas de auditoria. Em seguida, 2011 foram realizadas 41 trocas de firma de auditoria, em 2013 e 2014 realizaram-se 37 trocas, seguido de 2016 com 34 trocas, 2015 com 31 trocas e, por fim, 2010 com apenas 27 rodízios de firma de auditoria.

A fim de analisar se há diferença estatisticamente significativa no nível de gerenciamento de resultados entre o conjunto de empresas que realizaram troca de empresas de auditoria e as suas contrapartes (que não realizaram troca de empresas de auditoria), aplicou-se o teste $t$ de student e o teste de Levene, o qual é apresentado na tabela 5 .

Tabela 5. Teste de médias do gerenciamento de resultados

\begin{tabular}{|l|c|c|c|c|c|c|c|}
\hline \multirow{2}{*}{ Empresas } & \multirow{2}{*}{ Média $\Delta \mathrm{NI}$} & \multirow{2}{*}{ Variância } & \multicolumn{3}{|c|}{ Teste de Levene } & \multicolumn{3}{|c|}{ Teste- $t$ para Igualdade de Médias } \\
\cline { 4 - 8 } & & & $F$ & Sig & $t$ & $d f$ & Sig \\
\hline Com Troca & $-0,0083$ & Variâncias iguais assumidas & 0,0180 & 0,8930 & $-0,9240$ & 1618 & 0,3560 \\
\hline Sem Troca & 0,0032 & Variâncias iguais não assumidas & & & $-1,2650$ & 1366 & 0,2060 \\
\hline
\end{tabular}

Legenda: $\Delta \mathrm{NI}=$ Variabilidade no Lucro Operacional Líquido.

Fonte: Dados da pesquisa. 
Conforme se observa na tabela 5, a média do gerenciamento de resultados nas empresas em que não houve troca da firma de auditoria é de 0,0032 e para as empresas em que houve a troca da firma de auditoria é de -0,0083. Ademais, a tabela 5 apresenta o teste de Levene para a homogeneidade das variâncias. Fávero, Belfiore, Silva e Chan (2009) explicam que o teste de Levene é utilizado para testar a igualdade das variâncias populacionais entre dois grupos. Assim sendo, quando o teste se mostrar significativo, conclui-se que as variâncias são significativamente diferentes, utilizando-se os dados das variâncias iguais não assumidas. Porém, quando o teste de Levene não se mostrar significativo, deve-se aceitar a igualdade das variâncias, utilizando-se os dados das variâncias iguais assumidas.

Nesse sentido, o p-value do teste de Levene obtido foi 0,8930 , indicando que as variâncias são homogêneas e assim a estatística de teste a utilizar para o teste de $t$-Student é a que assume variâncias iguais. Desta forma, pode-se inferir que não há diferença estatística no gerenciamento de resultados das empresas que realizaram a troca de firma de auditoria em relaçáo às empresas que não realizaram.

\subsection{Análise de regressáo de dados em painel}

Nesta subseção apresenta-se a análise de regressão de dados em painel. No entanto, esta técnica necessita responder aos pressupostos de aleatoriedade, normalidade, homoscedasticidade e multicolinearidade dos dados. O teste de Durbin-Watson (DW) apresentou-se próximo ao valor de 2 (Marôco, 2011) evidenciando a inexistência de autocorrelação entre os resíduos, o que atende aos pressupostos de aleatoriedade. A partir de teste de Shapiro-Wilk (SW) examinou-se a normalidade dos dados (Fávero et al., 2009) cujo resultado apresentado indicou que a distribuição dos resíduos é normal. Já por meio do teste de Levene (F) verificou-se

a homoscedasticidade dos dados, apresentando uniformidade na variância dos erros. E por fim, por meio do VIF, a análise indicou que não há multicolinearidade dos dados. Desta forma, o modelo proposto atendeu a todos os pressupostos da técnica de regressão.

$\mathrm{Na}$ análise de dados em painel, inicialmente realizou-se a análise de dados de regressão por efeitos fixos (Fixed-effects) e em seguida o de efeitos aleatórios (Rondom-effects), para verificar o modelo mais adequado aos dados do estudo. Posteriormente aplicou-se o teste de LM de Breusch-Pagan e o teste de Chow com o intuito de verificar o modelo mais adequado. Como o teste de LM de Breusch-Pagan não foram significativos ao nível de 5\% e o teste de Chow foi significativo ao nível de 5\%, determinou-se que o modelo mais adequado à esta técnica é o de efeitos fixos (Fixed-effects). A partir destes pressupostos, apresenta-se na tabela 6 a análise de regressão em painel.

É possível verificar, conforme a tabela 6 , que o $\mathrm{F}$ de significação para o modelo de dados em painel, apresentou-se significativo ao nível de 5\% (Prob $>\mathrm{F}=$ 0,0000). Quando analisado o poder de explicação do modelo proposto, o coeficiente de determinação $\left(\mathrm{R}^{2}\right.$ Within) apresentou valor de 0,0345 , que significa que as variáveis independentes são responsáveis por 3,45\% na explicação do modelo. Conforme análise do Modelo 1, somente as variáveis GROWTH (percentual de mudanças nas vendas) e TURN (vendas divididas pelos ativos totais no final do ano) foram significativas a nível de 99\%, enquanto as demais variáveis não foram significativas no modelo.

A variável GROWTH (Percentual de mudanças nas vendas) apresentou um coeficiente de 0,0045 ou seja $0,45 \%$, sendo seu sinal positivo, o que indica que empresas com maior crescimento estão menos propensas ao gerenciamento de resultados. Este resultado 
Tabela 6. Análise de regressáo de dados em painel

\begin{tabular}{|c|c|c|c|c|}
\hline \multirow{2}{*}{ Variáveis } & \multirow{2}{*}{ Coeficiente } & \multirow{2}{*}{ Sig. } & \multicolumn{2}{|c|}{ Estatística de Colinearidade } \\
\hline & & & Tolerância & VIF \\
\hline SIZE & $-0,0033$ & 0,086 & 0,7980 & 1,25 \\
\hline GROWTH & $0,0045^{* * *}$ & 0,000 & 0,9972 & 1,00 \\
\hline LEV & 0,0001 & 0,234 & 0,9955 & 1,00 \\
\hline DISSUE & 0,0012 & 0,351 & 0,9964 & 1,00 \\
\hline TURN & $0,0580^{* * *}$ & 0,001 & 0,9431 & 1,06 \\
\hline $\mathrm{CF}$ & 0,0004 & 0,912 & 0,9996 & 1,00 \\
\hline AUD & 0,0118 & 0,255 & 0,8360 & 1,20 \\
\hline TROFIRAUD & $-0,0020$ & 0,723 & 0,9936 & 1,01 \\
\hline CONST. & $-0,0013$ & 0,992 & - & - \\
\hline Observações & \multicolumn{2}{|c|}{1620} & & \\
\hline $\mathrm{R}^{2}$ Within & \multicolumn{2}{|c|}{0,0345} & & \\
\hline Significância do Modelo (Prob > F) & \multicolumn{2}{|c|}{0,0000} & & \\
\hline LM de Breusch-Pagan & \multicolumn{2}{|c|}{0,1182} & & \\
\hline F de Chow & \multicolumn{2}{|c|}{0,0000} & & \\
\hline Teste de Hausman & \multicolumn{2}{|c|}{0,0000} & & \\
\hline
\end{tabular}

Legenda: ${ }^{*}$ significativo a $0,1(90 \%) ;{ }^{* *}$ significativo a $0,05(95 \%) ;{ }^{* *}$ significativo a $0,01(99 \%)$. SIZE = Logaritmo natural do ativo total; GROWTH $=$ Percentual de mudanças nas vendas; LEV = Total do passivo dividido pelo total do patrimônio líquido no final do ano; DISSUE = Percentual de mudanças no total dos passivos; TURN = Vendas divididas pelos ativos totais no final do ano; $\mathrm{CF}=$ Fluxo de caixa líquido anual das atividades operacionais divido pelos ativos totais no final do ano; AUD = Variável dicotômica (1 para empresa auditada por firma de auditoria Big-Four e zero para outras firmas de auditoria); TROFIRAUD = Variável dicotômica (1 para ano da troca de firma de auditoria e zero para o ano em que não houve troca de firma de auditoria).

Fonte: Dados da pesquisa.

está em linha como os achados no estudo de Bonfim, Silva, Gonçalves e Silva (2016) apesar de náo significativo. $\mathrm{O}$ autor explica que este resultado contraria os pressupostos da literatura que indicam o contrário, ou seja, empresas que estão em pleno crescimento tendem à maior propensão ao gerenciamento de resultados (Bonfim et al., 2016). No entanto, o resultado alcançado por esta pesquisa contraria tal pressuposto uma vez que o coeficiente apresentado foi de 0,0580 (5,80\%), sendo seu sinal positivo, ou seja, a variável TURN indica uma diminuição do gerenciamento de resultados.

Em relação à variável SIZE (logaritmo natural do ativo total), os resultados indicam um coeficiente de
$-0,0033(-0,33 \%)$. Apesar de baixo valor, e ainda não significativo, cabe destacar que seu sinal (negativo), pode-se inferir que quanto maior a seguradora, maior a possibilidade de gerenciamento de resultados. Este resultado é contrário ao evidenciado no estudo de Bonfim, Silva, Gonçalves e Silva (2016) o qual indicou que quanto maior a empresa, maior a possibilidade de gerenciamento de resultado. Esta divergência pode estar associada ao viés de setor, uma vez que o estudo comparativo foi realizado no setor de seguros, o qual é fortemente regulamentado, o que sugere que grandes seguradoras evitam tal procedimento, a fim de evitar problemas em relação à regulamentação inerente ao setor. 
As variáveis Endividamento (LEV) e Percentual de mudanças no total dos passivos (DISSUE) apresentaram respectivamente coeficientes de 0,0001 $(0,01 \%)$ e $0,0012(0,12 \%)$ que, apesar de não significativo, seus sinais positivos indicam um menor incentivo às organizaçóes quanto ao gerenciamento de resultados. Tais resultados são contrários aos evidenciados pela literatura, uma vez que empresas altamente endividadas e/ou alta variação dos seus passivos possuem fortes incentivos a tal prática (Bonfim et al., 2016). Já em relação ao Fluxo de caixa líquido anual das atividades operacionais divido pelos ativos totais no final do ano (CF) apresentou coeficientes de 0,0004 (0,04\%) que, também não sendo significativo, seu sinal positivo indica um menor incentivo às organizaçóes quanto ao gerenciamento de resultados. Klann e Beuren (2015) explica que empresas com fluxo de caixa menores tendem a apresentar maior gerenciamento de resultados, o que não evidenciado pela presente pesquisa.

Quanto à variável AUD (empresa auditada por firma de auditoria Big-Four ou não Big Four), foi apresentado o coeficiente 0,0118 (1,18\%), náo sendo esta variável significativa. Cabe destacar se seu sinal positivo indica que empresas auditadas por empresas de auditoria classificadas como Big-Four, possuem menor propensão a se utilizarem de gerenciamento de resultados, pois a literatura sugere que empresas que são auditadas por grandes empresas de auditoria obtém maior qualidade nas informaçóes e por consequência reduçáo nos níveis de gerenciamento de resultados (Bonfim et al., 2016). Tal resultado corrobora com o estudo de Azevedo e Costa (2012), não encontraram evidências estatisticamente significativas de que empresas auditadas por Big-Four impactam no nível de gerenciamento de resultados.

Por fim, a troca de empresa de auditoria (TROFIRAUD - ano da troca de firma de auditoria ou não houve troca) apresentou coeficiente de $-0,0020(0,02 \%)$, não apresentaram significância estatística, o que não indica um efeito desta variável no gerenciamento de resultados, corroborando com os resultados alcançados pelos estudos de Becker, DeFond, Jiambalvo e Subramanyam (1998), Silva e Bezerra (2010) e Azevedo e Costa (2012). No entanto, apesar de não significativo, o sinal do coeficiente (negativo) está me linha com o preconizado pela literatura de que empresas que efetuam a troca de empresa de auditoria, como sugerido pela Instruçấo CVM no 308 de 15 de maio de 1999 (CVM, 2017), pode ser indícios de que possa de alguma forma, reduzir a prática de gerenciamento de resultados.

Em suma, respondendo ao objetivo proposto por este estudo em verificar o efeito da troca de firma de auditoria no gerenciamento de resultados das empresas listadas na BM\&FBovespa no período de 2010 a 2016, verificou-se que não há efeito significativo no nível de gerenciamento de resultados.

\section{Consideraçóes finais}

A literatura revisitada preconiza que a troca da firma de auditoria contribui para o aumento da independência da empresa de auditoria em relação à empresa auditada bem como um instrumento para a redução do gerenciamento de resultados, uma vez que o novo auditor pode se apresentar mais céticos em relação às demonstrações contábeis, aumentando dessa forma a qualidade das demonstraçóes contábeis.

Sendo assim, o objetivo do presente estudo foi verificar o efeito da troca da firma de auditoria no gerenciamento de resultados das empresas brasileiras. Para isso, utilizou o modelo de Barth, Landsman e Lang (2008) e analisou-se a variabilidade do lucro operacional líquido anualmente. A população compreendeu as companhias abertas listadas na BM\&FBovespa, que 
estavam ativas no ano de 2017, sendo analisadas 264 empresas no período de 2010 a 2016, gerando um total de 1620 observaçóes. Para a análise dos dados, utilizou-se a técnica de regressão em dados em painel.

Os resultados encontrados evidenciaram que as variáveis GROWTH (percentual de mudanças nas vendas) e TURN (vendas divididas pelos ativos totais no final do ano) foram significativas a nível de $99 \%$, o que permite afirmar que estas impactam no gerenciamento de resultados nas organizaçôes que compóe a amostra no período analisado. Em contrapartida, demais variáveis SIZE (logaritmo natural do ativo total), LEV (total do passivo dividido pelo total do patrimônio líquido no final do ano), DISSUE (percentual de mudanças no total dos passivos), CF (fluxo de caixa líquido anual das atividades operacionais divido pelos ativos totais no final do ano), AUD (empresa auditada por firma de auditoria Big-Four ou não) e TROFIRAUD (troca de firma de auditoria) não foram significativas no modelo proposto.

Como forma de responder ao objetivo proposto pela presente pesquisa, os resultados que a troca da firma de auditoria não possui efeito significativo no gerenciamento de resultados das empresas que compóem a amostra deste estudo. Além disso, pode-se afirmar que o tipo de firma de auditoria (Big-Four e Não Big-Four) náo impacta, da mesma forma, no gerenciamento de resultados. Nesse sentido, as evidências corroboram os achados de Becker, DeFond, Jiambalvo e Subramanyam (1998), Silva e Bezerra (2010), Martinez e Reis (2011) e Azevedo e Costa (2012). Tais resultados foram constatados tanto para as empresas que realizaram a troca de firmas de auditoria quanto para aquelas que não realizam a troca.

Este estudo contribui para a literatura acerca da troca de firma de auditoria, demonstrando que não há uma relaçáo direta entre a troca de firma de auditoria e o gerenciamento de resultado, especificamente das empresas brasileiras listadas na BM\&FBovespa. Os resultados também contribuem para a crescente literatura examinando o gerenciamento de resultado, em particular, nosso estudo sugere, por meio do teste de médias, que não há diferença estatisticamente significativa no gerenciamento de resultados nos anos que há troca de firma de auditoria em relação aos anos que não há a troca.

Como limitação da pesquisa aponta-se que os resultados obtidos só podem ser aplicados para a amostra que compóe este estudo, não podendo ser generalizados a todas as empresas. Além disso, outras variáveis endógenas não contempladas nesse estudo, poderiam exercer influência nos resultados alcançados, mas entende-se que as limitaçóes listadas não invalidam os resultados dessa pesquisa.

Para futuras pesquisas sugere-se testar o efeito da troca de firma de auditoria no gerenciamento de resultados utilizando o modelo de Barth, Landsman e Lang (2008), com a aplicaçáo de outras métricas, além da aplicação ou alteração na amostra da pesquisa, que permite a utilização deste estudo para fins de comparabilidade dos resultados com outros países, e utilização de outras variáveis apontadas na literatura como fatores que verificam o efeito troca da firma de auditoria no gerenciamento de resultados.

\section{Referências}

Arrunada, B. \& Paz-Ares, C. (1997). Mandatory rotation of company auditors: A critical examination. International Review of Law and Economics, 17(1), 31-61. https://doi.org/10.1016/S0144-8188(96)00063-4

Azevedo, F. B. \& Costa, F. M. da. (2012). Efeito da troca da firma de auditoria no gerenciamento de resultados das companhias abertas brasileiras. Revista de 
Administração Mackenzie, 13(5), 65-110. https://doi. org/10.1590/S1678-69712012000500004

Barth, M. E., Landsman, W. R. \& Lang, M. H. (2008). International accounting standards and accounting quality. Journal of Accounting Research, 46(3), 467-498. https://doi.org/10.1111/j.1475-679X.2008.00287.x

Becker, C. L., DeFond, M. L., Jiambalvo, J. \& Subramanyam, K. R. (1998). The effect of audit quality on earnings management*. Contemporary Accounting Research, 15(1), 1-24. https://doi.org/10.1111/j.19113846.1998.tb00547.x

Bispo, O. N. D. A. \& Lamounier, W. M. (2011). Gerenciamento de resultados contábeis e o desempenho das ofertas públicas subsequentes de ações de empresas brasileiras. In $11^{\circ}$ Congresso USP de Controladoria e Contabilidade, 28 e 29. Anais... São Paulo/S.P.

BM\&FBovespa. Bolsa de Valores do Estado de São Paulo. 2017.Disponívelem:http://www.bmfbovespa.com.br/ cias-listadas/empresas-listadas/BuscaEmpresaListada. aspx?Idioma=pt-br. Acesso em: 27 set. 2017.

Bonfim, M. P., Silva, J. P. da, Gonçalves, R. de S. \& Silva, C. A. T. (2016). Adoção ao padrão IFRS e suavização dos resultados nas seguradoras brasileiras. Revista Universo Contábil, 12(4), 152-171. https://doi.org/10.4270/ ruc. 2016432

Catanach Jr, A. H. \& Walker, P. L. (1999). The international debate over mandatory auditor rotation: A conceptual research framework. Journal of International Accounting, Auditing and Taxation, 8(1), 43-66. https://doi. org/10.1016/S1061-9518(99)00004-X

Chi, W., Huang, H., Liao, Y. \& Xie, H. (2009). Mandatory Audit Partner Rotation, Audit Quality, and Market Perception: Evidence from Taiwan. Contemporary Accounting Research, 26(2), 359-391. https://doi. org/10.1506/car.26.2.2

Chow, G. C. (1960). Tests of equality between sets of coefficients in two linear regressions. Econometrica: Journal of the Econometric Society, 28(3), 591-605. https://doi. org/10.2307/1910133
Coelho, A. C. D. \& Lopes, A. B. (2007). Avaliação da prática de gerenciamento de resultados na apuraçáo de lucro por companhias abertas brasileiras conforme seu grau de alavancagem financeira. Revista de Administração Contemporânea, 11(2), 121-144. https://doi.org/ 10.1590/S1415-65552007000600007

Cunha, P. R. D., Klann, R. C., Rengel, S. \& Scarpin, J. E. (2011). Procedimentos de auditoria aplicados pelas empresas de auditoria independente de Santa Catarina em entidades do Terceiro Setor. Revista de Contabilidade e Organizaçôes, 4(10), 65-85. https:// doi.org/10.11606/rco.v4i10.34777

CVM. Comissão de Valores Mobiliários. 2017. Disponível em <http://www.cvm.gov.br/legislacao/instrucoes/ inst308.html>. Acesso em: 03 out. 2017.

Dani, A. C., Panucci Filho, L., dos Santos, C. A. \& Klann, R. C. (2017). Utilização de Provisôes para a Prática de Gerenciamento de Resultados em Empresas Brasileiras. Revista Evidenciação Contábil \& Finanças, 5(3), 37-56. https://doi.org/10.18405/recfin20170303

DeAngelo, L. E. (1981). Auditor independence,'low balling, and disclosure regulation. Journal of Accounting and Economics, 3(2), 113-127. https://doi.org/ 10.1016/0165-4101(81)90009-4

DeAngelo, L. E. (1986). Accounting numbers as market valuation substitutes: A study of management buyouts of public stockholders. Accounting Review, 61(3) 400-420.

Dechow, P. M. \& Sloan, R. G. (1991). Executive incentives and the horizon problem: An empirical investigation. Journal of Accounting and Economics, 14(1), 51-89. https://doi.org/10.1016/0167-7187(91)90058-S

Dechow, P. M., Sloan, R. G. \& Sweeney, A. P. (1995). Detecting earnings management. Accounting Review, 70(2), 193-225.

DeFond, M. L. \& Park, C. W. (1997). Smoothing income in anticipation of future earnings. Journal of Accounting and Economics, 23(2), 115-139. https://doi.org/ 10.1016/S0165-4101(97)00004-9

Contabilidad y Negocios (14) 28, 2019 / ISSN 1992-1896 
DeFond, M. L., Raghunandan, K. \& Subramanyam, K. R. (2002). Do non-audit service fees impair auditor independence? Evidence from going concern audit opinions. Journal of Accounting Research, 40(4), 12471274. https://doi.org/10.1111/1475-679X.00088

Fávero, L. P., Belfiore, P., Silva, F. L. \& Chan, B. L. (2009). Análise de dados: modelagem multivariada para tomada de decisóes. Rio de Janeiro: Elsevier, Campus.

Firmino, J. E., Damascena, L. G. \& Paulo, E. (2011). Qualidade da auditoria no Brasil: Um estudo sobre a atuação das auditorias independentes denominadas Big Four. Sociedade, Contabilidade e Gestão, 5(3), 40-50. https://doi.org/10.21446/scg_ufrj.v5i3.13215

Healy, P. M. (1985). The effect of bonus schemes of accounting decisions (Symposium on Management Compensation and the Manegerial laboratory Market). Journal of Accounting \& Economics. Rochester. 7(1-3), 85-107. https://doi.org/10.1016/0165-4101(85)90029-1

Healy, P. M. \& Wahlen, J. M. (1999). A review of the earnings management literature and its implications for standard setting. Accounting Horizons, 13(4), 365-383. https://doi.org/10.2308/acch.1999.13.4.365

Jones, J. J. (1991). Earnings management during import relief investigations. Journal of Accounting Research, 29(2), 193-228. https://doi.org/10.2307/2491047

Kang, S. H. \& Sivaramakrishnan, K. (1995). Issues in testing earnings management and an instrumental variable approach. Journal of Accounting Research, 33(2), 353-367. https://doi.org/10.2307/2491492

Kinney, W. R., Palmrose, Z. V. \& Scholz, S. (2004). Auditor Independence, Non-Audit Services, and Restatements: Was the US Government Right? Journal of Accounting Research, 42(3), 561-588. https://doi. org/10.1111/j.1475-679X.2004.t01-1-00141.x

Klann, R. C. \& Beuren, I. M. (2015). The Impact of the International Accounting Convergence on Income Smoothing in Brazillian Companies. BBR-Brazilian Business Review, 12(2), 1-24 https://doi.org/10.15728/ bbr.2015.12.2.1
Leuz, C., Nanda, D. \& Wysocki, P. D. (2003). Earnings management and investor protection: an international comparison. Journal of Financial Economics, 69(3), 505527. https://doi.org/10.1016/S0304-405X(03)00121-1

Lopes, A. B. \& Tukamoto, Y. S. (2007). Contribuição ao estudo do "gerenciamento" de resultados: uma comparação entre as companhias abertas brasileiras emissoras de ADRs e não-emissoras de ADRs. Revista de Administração da Universidade de São Paulo, 42(1), 86-96.

Marassi, R. B., Brizolla, M. M. \& da Cunha, P. R. (2014). Produção Científica Sobre Rodízio de Auditoria: Uma Análise Bibliométrica e Sociométrica nas Bases Sciense Direct e Scopus. Revista Evidenciação Contábil హ Finanças, 2(1), 4-21. https://doi.org/10.18405/ recfin 20140101

Marôco, J. (2011). Análise estatística com SPSS statistics. $5^{\mathrm{a}}$ ed. Pêro Pinheiro.

Martinez, A. L. (2001). "Gerenciamento" dos resultados contábeis: estudo empírico das companhias abertas brasileiras (Doctoral dissertation). Universidade de São Paulo.

Martinez, A. L. (2006). Minimizando a variabilidade dos resultados contábeis: estudo empírico do income smoothing no Brasil. Revista Universo Contábil, 2(1), 09-25.

Martinez, A. L. (2008). Detectando earnings management no Brasil: estimando os accruals discricionários. $R$. Cont. Fin. - USP - São Paulo, 19(46), 7-17. https:// doi.org/10.1590/S1519-70772008000100002

Martinez, A. L. \& Reis, G. M. R. (2011). Rodízio das firmas de auditoria e o gerenciamento de resultados no Brasil. Revista de Contabilidade e Organizaçóes, 4(10), 48-64. https://doi.org/10.11606/rco.v4i10.34776

Mattos, M. S. (2005). Os auditores no Brasil e a satisfação desses profissionais nas grandes empresas de auditoria. $145 \mathrm{f}$, il. Dissertação (Mestrado em Ciências Contábeis) - Programa de Pós-Graduação em Ciências Contábeis, Centro de Ciências Sociais Aplicadas, 
Universidade Regional de Blumenau, Blumenau, 2005. Disponível em: <http://www.bc.furb.br/docs/ TE/2005/314531_1_1.pdf>. Acesso em: 21 set. 2014.

Murcia, F. D. R., Borba, J. A. \& Schiehll, E. (2008). Relevância dos red flags na avaliaçáo do risco de fraudes nas demonstraçôes contábeis: a percepção de auditores independentes brasileiros. Revista Universo Contábil, $4(1), 25-45$.

Oliveira, A. Q. \& Santos, N. M. B. F. (2007). Rodízio de firmas de auditoria: a experiência brasileira e as conclusões do mercado. R. Cont. Fin. - USP - São Paulo, 18(45), 91-100. https://doi.org/10.1590/S1519-7077 2007000400009

Pae, J. (2005). Expected accrual models: the impact of operating cash flows and reversals of accruals. Review of Quantitative Finance and Accounting, 24(1), 5-22. https://doi.org/10.1007/s11156-005-5324-7

Quevedo, M. C. \& Pinto, L. J. S. (2014). Percepção do Rodízio de Auditoria sob o olhar dos Auditores Independentes. Revista Catarinense da Ciência Contábil, 13(38), 09-22. https://doi.org/10.16930/2237-7662/ rccc.v13n38p9-22

Said, K. \& Khasharmeh, H. (2014). Auditor's perceptions on impact of mandatory audit firm rotation on auditor independence Evidence from Bahrain. Journal of Accounting and Taxation, 6(1), 1-18. https://doi. org/10.5897/JAT2013.0127

Schipper, K. (1989). Earnings management. Accounting Horizons. 3(4), 91-102.

Silva, A. G. \& Robles Junior, A. (2008). Os impactos na atividade de auditoria independente com a introdução da lei Sarbanes-Oxley. R. Cont. Fin.- USP - São Paulo, 19(48), 112-127. https://doi.org/10.1590/ S1519-70772008000300010

Silva, J. O. \& Bezerra, F. A. (2010). Análise do Gerenciamento de Resultados e o Rodízio de Firmas de Auditoria nas Empresas de Capital Aberto. Revista Brasileira de Gestão de Negócios, 12(36), 304-321.

Zhang, Y., Zhou, J. \& Zhou, N. (2007). Audit committee quality, auditor independence, and internal control weaknesses. Journal of Accounting and Public Policy, 26(3),300-327. https://doi.org/10.1016/j.jaccpubpol. 2007.03.001

Fecha de recepción: 27 de octubre de 2017 Fecha de aceptación: 20 de diciembre de 2018 Correspondencia: pauloccsa@furb.br mauricio.leite@ymail.com vaniar.moras@gmail.com 